\title{
Thermen und Rubel
}

\section{Erhard Taverna}

Dr. med., Mitglied der Redaktion

Die Kurstadt im Schwarzwald lebt von Kongressen, Bädern und Russen. Ältere Menschen an Stöcken, junge Teilnehmer eines Lehrganges der Krankenkassen, ein Roche-Seminar, Wirtschaftsprüfer, Finanzberater, abends am Hotelempfang russische Familien mit einer Heliumflasche für die anstehende Party. Auffallend viele Apotheken sichern den Medikamentennachschub. Das späte Novemberlaub der Bäume durchdringen abwechselnd Sonne und Nebel.

Im 19. Jahrhundert war Baden-Baden die Sommerhauptstadt Europas, ein souveräner Staat, Hochburg des Liberalismus, Treffpunkt der fine fleur, wie Ivan Turgenev (1818-1883) die promenierenden Gäste auf der Lichtentaler Allee nannte. Die Parkanlage hat alle Kriegswirren überstanden, heute eine Museumsmeile mit einer hervorragenden Ausstellung zum 200. Geburtstag des Schriftstellers, der sieben Jahre im Bäderort verbrachte. Russland in Europa - Europa in Russland feiert den grossen Kulturvermittler zwischen Ost und West. Was ihn heute erstaunlich aktuell erscheinen lässt, ist das überlieferte Streitgespräch zwischen ihm und Fjodor Dostojewski (1821-1881). Nachgespielt als Film, geht es um den ewigen Gegensatz von Westlern und Slavophilen. Hier der eine, der die heilige, russische, messianische Seele scharf vom dekadenten Westlertum abgrenzt, dort der andere, der sich etwas von der Erfindungsgabe und Dynamik Europas für seine Heimat wünscht. Beide Autoren hatten die Weltausstellung von 1851 in London besucht. Für Turgenev war es ein vorbildlicher Höhepunkt menschlichen Erfindergeistes, seinem Kontrahenten machte sie Angst, er sah darin das biblische Babylon, die verwirklichte Apokalypse. Unversöhnliche Positionen mit persönlichen Ausfällen der Streitenden, die einander Spielschulden (Dostojewski) oder mangelnde Bucherfolge (Turgenev) vorwarfen. Turgenev hat die Hälfte seines Lebens in Europa verbracht. In seinem Roman aus Baden-Baden mit dem Titel Rauch schildert er gnadenlos seine kurenden Landsleute als Versager, Diebe, Betrüger, Parasiten und katzenbuckelnde Aristokraten, die zu Hause auf ihren Gütern die Leibeigenen prügeln. Sein vorletzter Roman, teilweise seine eigene Liebesgeschichte, war zunächst ein Misserfolg und in Moskau für einige Jahre verboten. Das Buch wurde Anfang der 1990er Jahre im gleichen Modeort der Belle Époque verfilmt. Beste Reklame für eine Tradition, die selbst zu

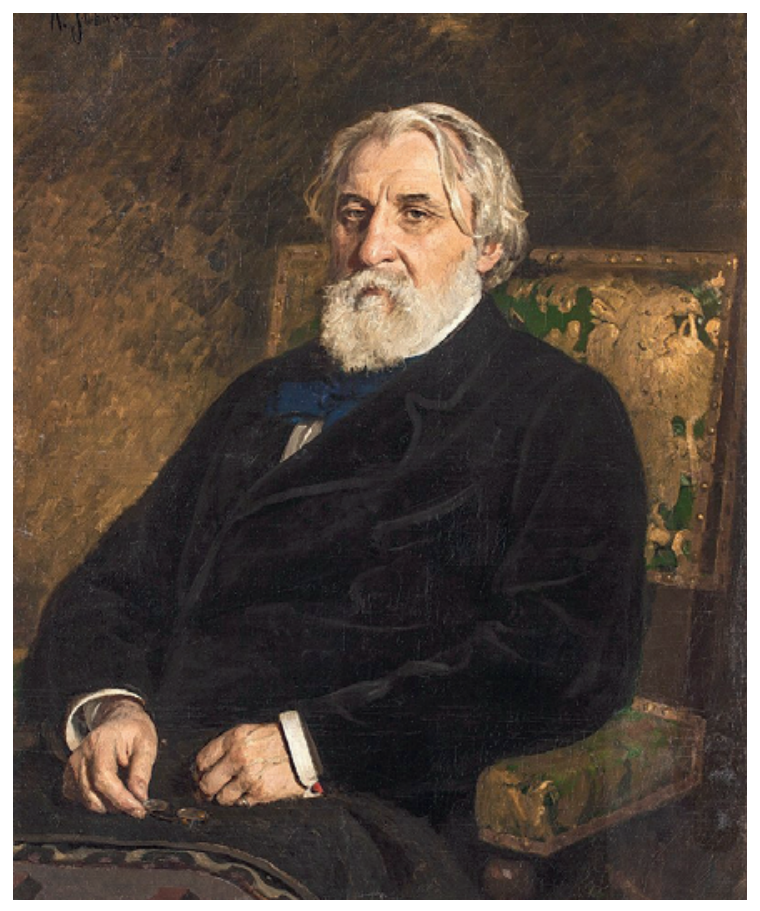

Die Thermalquellen sprudeln, von menschlichen Triumphen und Abgründen unberührt, aus der Tiefe. Natrium, Chlorid, Fluor, Kieselsäure, Arsen und Bor versprechen Heilkraft und den Erhalt der Gesundheit. Das historische Friedrichsbad und die Caracalla Therme bieten römische Badekultur und irische Heissluftbäder. Zahlreiche Kliniken und Kurhäuser profitieren davon. Die Werbebroschüren How do you say "vitality» in German? und The good-good life preisen überschwänglich das Wunder unberührter Natur verbunden mit High-Tech-Medizin, Theater und Konzertkultur. Die Innenstadt ist herausgeputzt, nachts werden die Kolonnaden vieler Bauten angestrahlt. Dank russischem Geld wurde mancher heruntergekommene Hotelbau wieder aufgemotzt. Die alten Kästen dienten als Lazarett und Unterkunft der französischen Besatzungsmacht. Stolpersteine erinnern, warum es dazu kam. Heute ist alles Wichtige kyrillisch angeschrieben, und viel Personal spricht fliessend die russische Sprache. Ivan Turgenev und Fjodor Dostojewski würden sich in dieser Stadt mühelos zurechtfinden. Alles steht noch am alten Platz und ist bequem zu Fuss erreichbar. Gegen die beklagte Langeweile jener früheren Epoche hilft das reichhaltige Amüsierprogramm der Moderne. Die Geschichte wiederholt sich nicht, aber viele Muster bleiben erstaunlich lebendig.

\section{Referenzen}

- Ausstellung «Russland in Europa - Europa in Russland», BadenBaden vom 22.9.2018 bis 3.3.2019.

- Turgenev I. Rauch. Ein Roman aus Baden-Baden. Hoffenberg, Neuausgabe Berlin; 2018.

\section{Bildnachweis}

Bild von Ivan Turgenev: https://de.wikipedia.org/wiki/Iwan Sergejewitsch_Turgenew\#/media/File:Turgenev_by_Repin.jpg; das Werk ist gemeinfrei. 